\title{
Control and physiological determinants of sympathetically mediated brown adipose tissue thermogenesis
}

\section{Denis Richard *, Boris Monge-Roffarello, Kanta Chechi, Sébastien M. Labbé and Eric E. Turcotte}

Centre de recherche de I'Institut universitaire de cardiologie et de pneumologie de Québec et Groupe interdisciplinaire de Recherche sur l'Obésité de I'Université Laval, Québec, QC, Canada

\section{Edited by:}

Patrick Seale, University of

Pennsylvania, USA

\section{Reviewed by:}

Miguel Lopez, University of Santiago de Compostela, Spain

Maristela De Oliveira Poletini,

University of Sao Paulo, Brazil

*Correspondence:

Denis Richard, Centre de recherche de I'Institut universitaire de cardiologie et de pneumologie de Québec, 2725 Chemin Sainte-Foy, Québec, QC, Canada G1V 4 G5.

e-mail:denis.richard@criucpq.ulaval.ca
Brown adipose tissue (BAT) represents a remarkable heat-producing tissue. The thermogenic potential of BAT is conferred by uncoupling protein 1, a protein found uniquely in brown adipocytes. BAT activity and capacity is controlled by the sympathetic nervous system (SNS), which densely innervates brown fat depots. SNS-mediated BAT thermogenesis is essentially governed by hypothalamic and brainstem neurons. BAT activity is also modulated by brain energy balance pathways including the very significant brain melanocortin system, suggesting a genuine involvement of SNS-mediated BAT thermogenesis in energy homeostasis. The use of positron emission tomography/computed tomography scanning has revealed the presence of well-defined BAT depots in the cervical, clavicular, and paraspinal areas in adult humans. The prevalence of these depots is higher in subjects exposed to low temperature and is also higher in women compared to men. Moreover, the prevalence of BAT decreases with age and body fat mass, suggesting that BAT could be involved in energy balance regulation and obesity in humans. This short review summarizes recent progress made in our understanding of the control of SNS-mediated BAT thermogenesis and of the determinants of BAT prevalence or detection in humans.

Keywords: energy balance, energy expenditure, melanocortin system, cold exposure, age, sex, environmental temperature, positron emission tomography

\section{INTRODUCTION}

Brown adipose tissue (BAT) is a specialized tissue whose main function is to produce heat. In small mammals, it is located in discrete depots and has largely been investigated for its role in thermogenesis (Cannon and Nedergaard, 2004; Sell et al., 2004a; Richard et al., 2010; Richard and Picard, 2011). The heat-producing capacity of BAT is such that it allows small mammals such as rats and mice to live at temperatures as low as $4^{\circ} \mathrm{C}$ without shivering.

The activation of BAT thermogenesis is under the strict control of the sympathetic nervous system (SNS). BAT is richly innervated by the postganglionic neurons of the efferent branches of the SNS (Bartness et al., 2010). These neurons release noradrenaline (NA), whose action on $\beta$-adrenergic receptors triggers the breakdown of triglycerides into fatty acids, which not only serve as energy source for thermogenesis but also act as the stimulators of BAT thermogenic activity (Nicholls and Locke, 1984). The SNS activity in BAT is governed by the brain autonomic centers including hypothalamus and brainstem, which are regions involved in the cold-induced thermogenesis (Morrison, 2011) and energy balance regulation (Richard, 2007; Richard and Picard, 2011).

We now have evidence that BAT is not only found in small mammals but also in adult humans (Nedergaard et al., 2007; Cannon and Nedergaard, 2010; Enerback, 2010a,b; Richard et al., 2010). A number of studies involving imaging procedures such as positron emission tomography/computed tomography (PET/CT) scanning have revealed symmetrical distribution of metabolically active brown fat depots around cervical, clavicular, and paraspinal regions in humans (Cypess et al., 2009; van Marken Lichtenbelt et al., 2009; Virtanen et al., 2009; Zingaretti et al., 2009). Recent progress has also been made in our understanding of various factors that affect the prevalence and activity of BAT in humans (Cypess et al., 2009; Saito et al., 2009; van Marken Lichtenbelt et al., 2009; Ouellet et al., 2011; Wang et al., 2011; Yoneshiro et al., 2011a).

This short article is aimed at reviewing (i) the brain circuits, essentially those pertaining to the metabolic brain melanocortin system, that control SNS-mediated BAT thermogenesis and (ii) our current understanding of the factors determining the prevalence or detection of BAT depots in humans.

\section{BAT THERMOGENESIS}

Brown adipose tissue was first observed in 1551 by the Swiss naturalist Konrad Gessner, who described it as being "neither fat nor flesh (nec pinguitudo nec caro)" (Gesner, 1551; Cannon and Nedergaard, 2008). The brownish appearance of BAT indeed contrasts with that of the white adipose tissue (WAT) whose role is to store lipids predominantly. Furthermore, brown adipocytes have a developmental origin that largely differs from that of the white adipocytes (Seale et al., 2008; Tseng et al., 2008). In that respect, brown but not white adipocytes develop from myogenic factor 5 (Myf5)-expressing myoblasts under the action of the transcription factor PRD1-BF1-RIZ1 homologous domain-containing 16 (PRDM16; Cannon and Nedergaard, 2008; Kajimura et al., 2010; Seale, 2010). The extraordinary thermogenic capacity of BAT is conferred by the presence of uncoupling protein 1 (UCP1), a protein uniquely found in the brown adipocytes. 
UCP1 is a mitochondrial inner membrane protein that is capable of uncoupling mitochondrial oxidation from ATP synthesis, in a process that triggers heat production through enhanced cellular respiration (Nicholls and Locke, 1984).

Owing to its tremendous thermogenic potential, BAT is viewed as a potential target to increase energy expenditure and combat obesity. Animal data support a role for BAT thermogenesis in energy homeostasis. Chronic reduction in SNS-mediated BAT thermogenesis parallels the reduction in energy expenditure exhibited by various animal models of obesity (also exhibiting enhanced energy intake) such as the leptin deficient $o b / o b$ mouse (Trayhurn et al., 1982), leptin-receptor deficient $d b / d b$ mouse (Goodbody and Trayhurn, 1981), leptin-resistant fa/fa rat (Marchington et al., 1983), and melanocortin-4 receptor (MC4R)-ablated obese mice (Ste et al., 2000; Balthasar et al., 2005). A decrease in SNS-mediated BAT thermogenesis associated with reduced energy expenditure has also been reported in animals seeking to spare energy such as rats subjected to energy restriction (Rothwell and Stock, 1982) as well as in lactating (Trayhurn and Richard, 1985) and pregnant rodents (Andrews et al., 1986).

Further support for the role of BAT in energy balance was the recent finding that $U c p 1$-ablated mice displayed a reduction in adaptive thermogenesis accompanied by an increase in fat gain, which was exacerbated by high-fat feeding (Feldmann et al., 2009). It is noteworthy that $U c p 1$-ablated mice gained excess fat only when they were housed at a thermoneutral temperature $\left(29^{\circ} \mathrm{C}\right)$. Interestingly, lack of UCP1 per se would apparently not increase metabolic efficiency in the Ucp1-deficient mice housed below $29^{\circ} \mathrm{C}$ (Kozak and Anunciado-Koza, 2008), except in old mice (Kontani et al., 2005), or in mice chronically fed an energy-dense palatable diet (Nedergaard et al., 2001). The absence of changes in the energy balance following Ucp1 loss/gain-of-function under certain circumstances, should not be considered to invalidate the importance of BAT in energy balance. It is important to consider that the complex brain circuitries controlling SNS-mediated BAT thermogenesis can and do activate alternative thermogenic pathways in animals with defective BAT. A well-developed/organized BAT thermogenic machinery can certainly be an asset upon which the brain can rely to efficiently control energy expenditure and hence regulate energy balance.

\section{BRAIN CIRCUITS INVOLVED IN SNS-MEDIATED CONTROL OF BAT THERMOGENESIS AND ENERGY HOMEOSTASIS}

Brown adipose tissue depots are richly innervated by SNS postganglionic neurons, and it is through the SNS, and hence via adrenergic receptors, that BAT thermogenesis is physiologically controlled (Cannon and Nedergaard, 2004; Bartness et al., 2010). Although thermogenic capacity of BAT can be significantly enhanced by the use of agents such as peroxisome proliferator-activated receptor $\gamma$ (PPAR $\gamma)$ agonists, the actual thermogenic activity of the tissue is critically dependent upon the adrenergic tone to BAT (Sell et al., 2004b; Festuccia et al., 2008). Cold exposure and overfeeding increases noradrenaline (NA) turnover rate in BAT (Landsberg et al., 1984) and, remarkably, neither cold nor overfeeding induce thermogenic activity in mice lacking $\beta$-adrenoreceptors $(\beta$-less mice; Bachman et al., 2002; Jimenez et al., 2002; Lowell and Bachman, 2003).
Sympathetic nervous system-mediated BAT thermogenesis is controlled by the hypothalamic and brainstem nuclei such as the preoptic area (POA), arcuate hypothalamic nucleus (ARC), paraventricular hypothalamic nucleus $(\mathrm{PVH})$, dorsomedial hypothalamic nucleus $(\mathrm{DMH})$, periaqueductal gray $(\mathrm{PAG})$, and raphé pallidus (RPA; Grill, 2006; Berthoud and Morrison, 2008; Richard et al., 2010; Morrison, 2011; Richard and Picard, 2011). All of these nuclei contain neurons expressing chemical mediators and receptors involved in the control of SNS-mediated BAT thermogenesis. The brain circuits involved in energy balance regulation differ slightly from those involved in thermoregulatory thermogenesis. The latter have been the subject of excellent reviews elsewhere (Morrison, 2011; Nakamura, 2011) and will not be discussed here. This section will review the recent advances made in our understanding of the melanocortin system, which represents the most significant regulator of energy homeostasis.

\section{THE MELANOCORTIN SYSTEM IS A KEY PLAYER IN THE CONTROL OF SNS-MEDIATED BAT THERMOGENESIS IN RELATION TO ENERGY HOMEOSTASIS}

The brain "metabolic" melanocortin system consists of (i) ARC neurons producing the proopiomelanocortin (POMC) fragment, $\alpha$-melanocyte-stimulating hormone $(\alpha \mathrm{MSH})$, (ii) neurons harboring the melanocortin receptor 4 (MC4R), (iii) and ARC neurons synthesizing agouti-related protein (AgRP), an endogenous antagonist of the MC4R. The ARC neurons that synthesize AgRP also express NPY, which is a well-recognized anabolic neuropeptide (Herzog, 2003; Nguyen et al., 2011). The "catabolic" role played by the brain melanocortin system has been acknowledged previously (Garfield et al., 2009; Mountjoy, 2010; Corander and Coll, 2011; De Jonghe et al., 2011; Pandit et al., 2011). Loss-of-function mutations of the key players of this system (for instance POMC or MC4R) have been reported to cause massive obesity in laboratory animals (De Jonghe et al., 2011) and humans (Farooqi and O'Rahilly, 2006; Tao, 2010).

It is noteworthy that ARC POMC and AgRP/NPY neurons are known to be leptin-sensitive, which further corroborates the role of the melanocortin system in energy homeostasis. Upon activation by leptin, POMC neurons release the catabolic fragment $\alpha$-MSH from nerve terminals found in several brain regions that express MC4R. Moreover, leptin inhibits AgRP/NPY neurons and MC4R deficiency has been shown to blunt the ability of leptin (be it injected centrally or peripherally) to increase Ucp1 expression in BAT and WAT (Zhang et al., 2005).

\section{HYPOTHETICAL MELANOCORTINERGIC CIRCUITS CONTROLLING SNS-MEDIATED BAT THERMOGENESIS}

In an attempt to delineate the circuits pertaining to the melanocortin system controlling SNS-mediated BAT thermogenesis, we have identified numerous brain populations of MC4R mRNA-harboring neurons that are polysynaptically (through several synapses) connected to BAT, using transneuronal viral retrograde tract-tracing technique (Song et al., 2008). It was estimated that 84,83 , and $77 \%$ of the neurons expressing MC4R found in the PVH, PAG, and POA brain regions, respectively, were connected to interscapular BAT in rats (Song et al., 2008). Since the absolute total number of neurons from each of these three region 
that connect to BAT is very high in, one can confidently infer that MC4R neurons found in the PVH, POA, and PAG brain regions are all unquestionably part of the circuits that control BAT thermogenesis (Morrison, 2011; Richard and Picard, 2011).

An increase in BAT thermogenesis was reported when MC4R agonist melanotan 2 (MT2) was injected in the PVH (Song et al., 2008), further demonstrating that the MC4R neurons of the PVH promote BAT-mediated thermogenesis. The phenotype of the MC4R neurons of PVH that are connected to BAT remains to be ascertained. However, it is likely that neurons expressing oxytocin (OT) and the cannabinoid receptor 1 (CB1; Richard et al., 2009; Gelez et al., 2010; Ghamari-Langroudi et al., 2011) could directly project to the intermediolateral column (IML) of the spinal cord in order to control the SNS neurons linked to BAT (Song et al., 2008). Recent data from our laboratory has further demonstrated that CB1 agonism can blunt MT2-induced oxygen consumption and UCP1 expression in BAT (Roffarello and Richard, unpublished results), pointing toward an interaction between the melanocortin and cannabinoid pathways in the regulation of BAT-mediated thermogenesis.

With $83 \%$ of its 1337 MC4R positive neurons (some 1165 neurons) synaptically linked to the iBAT (Song et al., 2008), the PAG would represent the next brain region (after PVH) containing the largest population of MC4R neurons connected to BAT (Song et al., 2008). This neuro-anatomical finding leaves little doubt about the potential involvement of PAG in the MC4Ragonism-mediated regulation of BAT thermogenesis. The ventrolateral division of the PAG has been reported to receive direct projections from the ARC (Guo and Longhurst, 2010; Li et al., 2010a) and then to project to the RPA (Li et al., 2010b), wherefrom 5-hydroxytryptamine neurons in turn were found to project to the IML, likely to control the SNS outflow to BAT (Morrison, 1999, 2011). In addition, other studies have demonstrated a direct involvement of the PAG in the regulation of BAT-mediated thermogenesis (de Menezes et al., 2006; Rathner and Morrison, 2006).

After the PVH, the POA comprises the second largest population of hypothalamic MC4R neurons that are connected to iBAT (Song et al., 2008). The role of the POA in regulating BAT thermogenesis has been acknowledged previously (Nakamura et al., 2005; Nakamura, 2011). However the neuronal circuits through which MC4R neurons of POA control BAT-mediated thermogenesis have yet to be delineated. The POA contains gamma-aminobutyric acid (GABA) neurons that project to the $\mathrm{DMH}$, where they inhibit excitatory neurons that send projections to the brainstem in order to connect with the premotor neurons governing the activity of the SNS efferent neurons (Nakamura et al., 2005; Morrison, 2011; Nakamura, 2011). Interestingly, similar to prostaglandin E2 (PGE2; Nakamura et al., 2005; Morrison, 2011; Nakamura, 2011), MC4R POA neurons could inhibit the POA GABA neurons projecting to the $\mathrm{DMH}$ to ultimately release their inhibition on neurons promoting SNS activity to BAT.

Overall, it is apparent that the melanocortin system exerts its control on the SNS-mediated BAT thermogenesis via various neuronal populations of hypothalamus and brainstem regions. Future studies would be required to better characterize these neurons and extend our current understanding on this subject.

\section{BAT IN ADULT HUMANS}

In the last decade, various studies using PET/CT scanning with ${ }^{18}$ fluorodeoxyglucose $\left({ }^{18} \mathrm{FDG}\right.$; often aimed at screening tumors) have demonstrated the presence of metabolically active fat depots within the cervical, supraclavicular, and paraspinal regions in adults humans (Nedergaard et al., 2007; Cannon and Nedergaard, 2010; Enerback, 2010a,b; Richard et al., 2010). These depots were characterized as being BAT with cells having multilocular cytoplasm and abundant mitochondria (Zingaretti et al., 2009). Moreover, these fat depots were reported to have rich SNS-innervations and to express Ucp1, the ultimate marker of the brown adipocytes (Cypess et al., 2009; van Marken Lichtenbelt et al., 2009; Virtanen et al., 2009; Zingaretti et al., 2009). Additionally, ${ }^{18}$ FDG-detected BAT was found to express mRNAs encoding other proteins such as type II iodothyronine deiodinase (DIO2), PPAR $\gamma$-coactivator- $1 \alpha$ $(\mathrm{PGC} 1 \alpha), \mathrm{PRDM} 16$, and $\beta 3$-adrenergic receptor (Virtanen et al., 2009), all of which are known to be the key players in mediating BAT thermogenesis.

The prevalence of ${ }^{18}$ FDG-detectable BAT is determined by a series of factors including age, sex, body mass index (BMI), outdoor temperature preceding PET/CT scanning and the diabetes status of the individuals. The detection of metabolically active BAT has been shown to (i) decrease with age (Cypess et al., 2009; Saito et al., 2009; Zingaretti et al., 2009), (ii) inversely correlate with BMI and fat content (Cypess et al., 2009; Saito et al., 2009; Zingaretti et al., 2009), (iii) increase with exposure to low temperatures (Cohade et al., 2003a; Garcia et al., 2006; Kim et al., 2008; Cypess et al., 2009; Saito et al., 2009), (iv) be higher in women than men (Cypess et al., 2009), and (v) to be lower in diabetic than non-diabetic patients (Cypess et al., 2009). In large cohorts of adult humans screened for cancer, the detection/prevalence of BAT was estimated to be relatively low (5-10\% and below; Cypess et al., 2009; Ouellet et al., 2011). This obviously represents an underestimation of the true prevalence of BAT. In fact, the presence of BAT is not ineluctably detectable during PET scans in cancer screening investigations, as BAT needs to be stimulated to exhibit ${ }^{18} \mathrm{FDG}$ uptake. The true prevalence of BAT is much higher than 5-10\% and we (Ouellet et al., 2012) and others (van Marken Lichtenbelt et al., 2009) have reported a near 100\% BAT prevalence in cold-exposed young human subjects. PET/CT investigations with large cohorts have nonetheless proved invaluable for meaningfully scrutinizing various determinants of the BAT prevalence.

\section{BAT DISTRIBUTION IN CHILDREN AND ADULT HUMANS DIFFERS FROM THAT OF HUMAN NEONATES AND SMALL MAMMALS}

The pattern of BAT distribution in adult humans differs from that seen in human neonates (Enerback, 2010a) and small laboratory rodents such as rats and mice (Cannon and Nedergaard, 2004). In contrast to rodents, humans do not possess a prominent interscapular BAT depot. In adult humans (Ouellet et al., 2011) as well as in children and adolescents (Drubach et al., 2011), the most easily detectable and the most prominent BAT depot is located in the supraclavicular area. This depot exhibited the highest ${ }^{18}$ FDG uptake activity following cold exposure (van Marken Lichtenbelt et al., 2009) and was also described as 


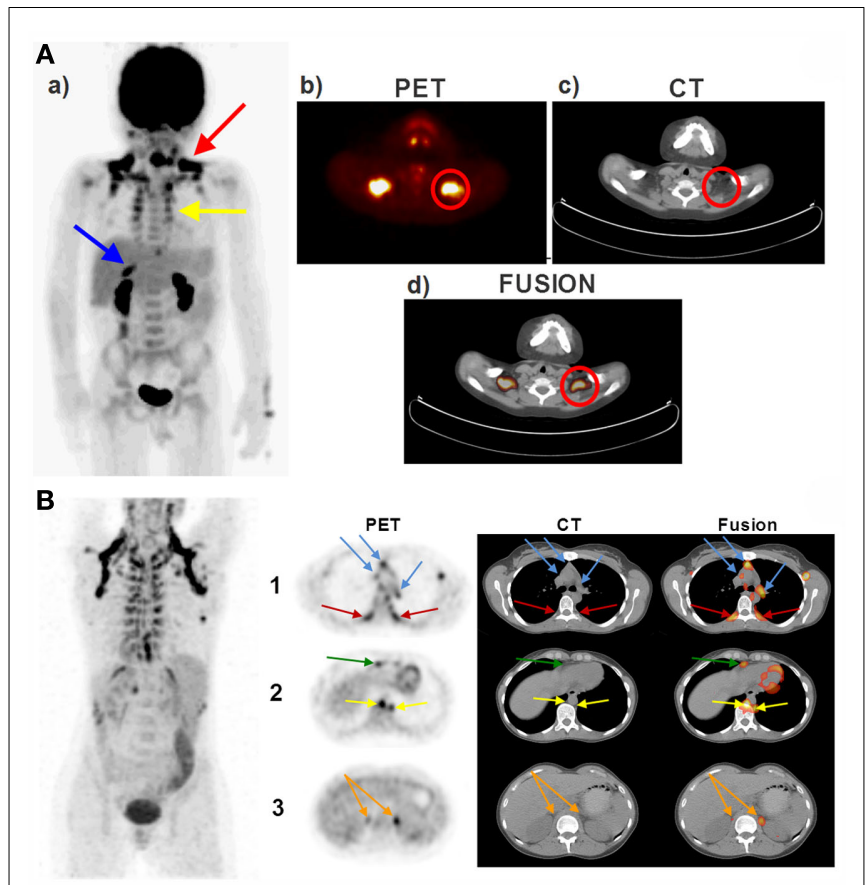

FIGURE 1 | Brown adipose tissue (BAT) distribution in a pediatric (A) and adult (B) human. (A) The PET/CT scans of a 5-year-old boy taken $60 \mathrm{~min}$ after an i.v. injection of $5 \mathrm{mCi}{ }^{18} \mathrm{FDG}$. Red arrow shows the supraclavicular BAT, yellow arrow shows the peri-spinal BAT depots and blue arrow shows the peri-adrenal BAT depot in (a) coronal view (postero-anterior projection). The Supraclavicular BAT is also illustrated in a transversal series of (b) PET, (c) CT, and (d) fusion views of the cervical-supraclavicular region. Red circles denote the supraclavicular BAT in (b-d). (B) The PET/CT scans of a 35-year-old woman taken 60 min after an i.v. injection of $5 \mathrm{mCi}{ }^{18} \mathrm{FDG}$. First row shows the transversal section of the aortic arch. Red arrows denote the peri-spinal BAT depots and the blue arrows point to the mediastinal BAT depots on PET (left panel), CT (middle panel), and fusion scans (right panel). Second row shows the transversal section of the hepatocardiac section, where yellow arrows point to the peri-aortic BAT depots and the green arrow points to the pericardial BAT depots. Third row shows the transversal section of the adrenal gland, where orange arrows point to the peri-adrenal BAT depots. PET/CT, positron emission tomography/computed tomography; ${ }^{18} \mathrm{FDG},{ }^{18}$ fluorodeoxyglucose; i.v., intravenous; BAT, brown adipose tissue.

the USA-fat (Uptake in Supraclavicular Area Fat) in one of the decisive studies identifying BAT using PET/CT scanning (Cohade et al., 2003b). In addition, BAT is also noticeably seen in the cervical and paraspinal areas in both children and in adults (Enerback, 2010a; Richard et al., 2010; Richard and Picard, 2011). Figure 1A demonstrates the PET/CT images of a 5 -year-old boy showing the presence of ${ }^{18}$ FDG uptake activity in various fat depots, whereas Figure 1B represents the PET/CT images of a 35-yearold women showing the presence of ${ }^{18}$ FDG-detectable BAT in the supraclavicular, peri-spinal, mediastinal-, pericardial, peri-aortic, and peri-adrenal sites. We (Chechi et al., unpublished observations) and others (Sacks et al., 2009; Sacks and Fain, 2011) have recently observed that human epicardial fat depot expresses significant levels of Ucp1, indicating that BAT is present around the heart.

\section{HUMAN BAT ACTIVITY IS UNDER THE CONTROL OF THE SNS}

The detection of ${ }^{18}$ FDG-detectable BAT in humans is also modulated by the use of $\beta$-blockers (Tatsumi et al., 2004; Jacobsson et al., 2005; Parysow et al., 2007; Soderlund et al., 2007; Cypess et al., 2009). Soderlund et al. (2007) demonstrated that a single dose of $80 \mathrm{mg}$ of propranolol (taken $2 \mathrm{~h}$ before FDG administration) led to the complete attenuation of ${ }^{18} \mathrm{FDG}$ uptake in BAT. On the other hand, patients with pheochromocytoma were reported to exhibit intense ${ }^{18}$ FDG uptake in BAT (Hadi et al., 2007; Kuji et al., 2008; Yamaga et al., 2008), which disappeared following the resection of the catecholamine-secreting tumors (Hadi et al., 2007; Yamaga et al., 2008).

\section{BAT PREVALENCE/DETECTION DECREASES WITH AGE}

Age represents a significant determinant of ${ }^{18}$ FDG-detectable BAT (Truong et al., 2004; Gelfand et al., 2005; Cypess et al., 2009; Saito et al., 2009). In cohorts of patients under cancer surveillance, people exhibiting ${ }^{18}$ FDG uptake sites were reported to be on average younger than those showing no sign of ${ }^{18} \mathrm{FDG}$-detectable BAT (Cypess et al., 2009; Zingaretti et al., 2009; Ouellet et al., 2011). In a recent investigation aimed at assessing the prevalence and determinants of BAT ${ }^{18}$ FDG uptake in children and adolescents screened for tumors, Drubach et al. (2011) reported prevalence of detectable BAT of above $40 \%$, with the highest BAT activity seen in the 13- to 15-years-old age group. A prevalence of above $40 \%$ in children/adolescents tested in conditions that do not necessarily activate BAT has to be considered as being high and much higher than that of $5-10 \%$ seen in cohorts of adult patients tested in similar conditions. Consistent with this, in our cohort of adult patients tested for cancer, we observed a decrease in the detection/prevalence of BAT with age in both men and women (Ouellet et al., 2011). In addition, Saito et al. (2009) reported a prevalence of cold-induced BAT ${ }^{18}$ FDG uptake in 52\% (16/31) of subjects aged between 23 and 35 years, compared to $8 \%(2 / 24)$ of subjects aged between 38 and 65 years. Altogether, the literature suggests that age reduces the thermogenic capacity of BAT, which renders BAT detection by PET/CT less probable (Richard et al., 2010).

\section{BAT PREVALENCE/DETECTION DECREASES WITH INCREASED FATNESS}

The detection of BAT appears strongly influenced by BMI and body fat in humans of all age groups (Cypess et al., 2009; Saito et al., 2009; van Marken Lichtenbelt et al., 2009; Drubach et al., 2011; Ouellet et al., 2011; Wang et al., 2011; Yoneshiro et al., 2011a). Specifically, BAT activity was reported to be inversely correlated to BMI (Cypess et al., 2009; Ouellet et al., 2011), body fat (Saito et al., 2009; van Marken Lichtenbelt et al., 2009; Yoneshiro et al., 2011a), and visceral obesity (Wang et al., 2011). Noteworthily, Saito et al. (2009) reported that the only two subjects with active BAT (out of 24) in an age group of 38-65 years were the two leanest subjects. The same investigators also provided evidence to support a negative association between BAT activity and the accumulation of body fat with age (Yoneshiro et al., 2011a). van Marken Lichtenbelt et al. (2009), who reported an inverse relationship between cold-induced ${ }^{18}$ FDG uptake activity in BAT with both BMI and percentage of body fat, emphasized that the sole subject (out of $24)$, who resisted cold-induced BAT ${ }^{18}$ FDG uptake in their study, 
was the one displaying the largest BMI (38.7) and percentage of body fat $(41.8 \%)$.

\section{BAT DETECTION/PREVALENCE INCREASES WITH LOW TEMPERATURE}

In addition to age and body fat mass, the outdoor temperature on the day of ${ }^{18}$ FDG PET/CT scanning may be a major determinant of BAT detection. Expectedly, the colder the temperature at the time of scanning, the higher is the prevalence of ${ }^{18}$ FDG-detectable BAT (Cohade et al., 2003a; Kim et al., 2008; Ouellet et al., 2011). Not surprisingly, this BAT prevalence varies with seasons, being higher in winter than in summer (Cohade et al., 2003a; Au-Yong et al., 2009; Cypess et al., 2009; Saito et al., 2009; Ouellet et al., 2011). Winter could enhance the stimulating effect of acute cold exposure on the ${ }^{18}$ FDG uptake in BAT (Saito et al., 2009), likely by increasing BAT capacity (Richard et al., 2010; Ouellet et al., 2011). The seasonal effects on BAT detection has also been linked to changes in the photoperiod (Au-Yong et al., 2009). However, we found that the outdoor temperature on the day of testing was a stronger determinant of BAT detection than the photoperiod (Ouellet et al., 2011). The notion that environmental temperature is a major determinant of ${ }^{18} \mathrm{FDG}$-detectable BAT prevalence is also consonant with the early data reported by Huttunen et al. (1981), who demonstrated a higher prevalence of BAT-related enzymes in the adipose tissue biopsies of outdoor workers compared to indoor workers.

\section{BAT DETECTION/PREVALENCE IS HIGHER IN WOMEN THAN MEN}

Sex represents another factor that influences BAT detection in humans, since women exhibit higher prevalence than men (Hany et al., 2002; Cohade et al., 2003b; Truong et al., 2004; Rousseau et al., 2006; Cypess et al., 2009). Cypess et al. (2009) reported positive scans for ${ }^{18}$ FDG uptake sites in 76 of 1013 women $(7.5 \%)$ and 30 of 959 men $(3.1 \%)$, corresponding to a female/male ratio of more than 2:1. We also observed a similar pattern of BAT prevalence in women compared to men in our cohort (Ouellet et al., 2011). In addition, women were reported to exhibit greater BAT mass and higher ${ }^{18}$ FDG uptake activity (Cypess et al., 2009). Interestingly, we observed that the sex effect on the detection/prevalence of BAT tended to disappear in aging humans (Ouellet et al., 2011), indicating the potential role of female sex hormones in BAT thermogenesis. In that respect, it is worth mentioning that the prevalence of detectable BAT did not differ between boys and girls prior to puberty (Drubach et al., 2011).

The reason as to why women exhibit a higher detection of ${ }^{18}$ FDG-BAT (after puberty and prior to menopause) is not known. The possibility however exists that women experience more cold sensation at a given temperature than men, which is supported by human and animal studies (Quevedo et al., 1998; Rodriguez et al., 2001; Rodriguez-Cuenca et al., 2002; Valle et al., 2007). This hypothesis needs to be further substantiated in future human cohorts.

\section{DIABETES LOWERS DETECTION OF BAT}

We recently demonstrated that prevalence of ${ }^{18} \mathrm{FDG}$-detectable BAT was lower in the diabetic subjects $(1.8 \%)$ than the nondiabetic subjects (11.5\%; Ouellet et al., 2011), which is in line with the observations made by Cypess et al. (2009). However, the mechanisms linking diabetes to a reduced detection of BAT remain to be delineated.

\section{BAT-MEDIATED THERMOGENESIS MAY REPRESENT A SIGNIFICANT ENERGY-CONSUMING PROCESS IN HUMANS}

Our recent series of experiments with ${ }^{11} \mathrm{C}$-acetate (Ouellet et al., 2012), a PET tracer used to assess tissue oxidative metabolism (Labbe et al., 2011), convincingly demonstrated the metabolic importance of BAT in non-shivering thermogenesis in young adults. Our subjects were studied under well-controlled cold exposure conditions designed to minimize shivering (Ouellet et al., 2012). We observed a significant 1.8-fold increase in the total energy expenditure (excess expenditure of some $250 \mathrm{kcal}$ over $3 \mathrm{~h}$ of cold exposure), which was suggested to be due, in large part, to an increase in BAT-mediated non-shivering thermogenesis associated with an increase in intracellular fat depletion. We indeed observed a significant increase in the radio-density of BAT after cold exposure, indicating that BAT triglyceride content was reduced by cold exposure (Ouellet et al., 2012). By demonstrating the involvement of BAT in the non-shivering thermogenesis of young adults, our results (Ouellet et al., 2012) add to the previous findings that BAT detection is reduced by aging and fatness, and lend further support for the participation of BAT in energy homeostasis. Incidentally, the relative difficulty in detecting adaptive thermogenesis in humans (Schoeller, 2001) does not necessarily argue against the role of BAT thermogenesis in energy homeostasis, as it parallels the difficulty in detecting BAT. Future metabolic studies conducted in the cold-adapted young individuals would possibly help to delineate the role of BAT thermogenesis in controlling energy expenditure in humans. Based on reasonable assumptions, Virtanen et al. (2009) estimated that annual energy expenditure associated with the submaximal stimulation of about $60 \mathrm{~g}$ of human BAT depot could burn more than $4 \mathrm{~kg}$ of body fat. Such an estimate is in line with that of Rothwell and Stock (1983), who pioneered the view that active brown fat can have profound influence on human energy metabolism.

\section{CONCLUSION}

Recent advances in our understanding of numerous brain pathways that drive the SNS outflow to BAT (Bartness and Song, 2007; Song et al., 2008; Bartness et al., 2010; Morrison, 2011; Richard and Picard, 2011) using sophisticated techniques like transneuronal viral retrograde tract-tracing have fueled the current interest in studying the brain systems involved in energy balance regulation (Bartness et al., 2010; Richard et al., 2010; Richard and Picard, 2011). One such system includes the brain metabolic melanocortin system, which acts via the activation of MC4R, thereby controlling energy expenditure while enhancing BAT thermogenesis (Ste et al., 2000; Butler, 2006). Numerous brain populations of MC4R mRNA-harboring neurons that are synaptically connected to BAT (Song et al., 2008) and WAT (Song et al., 2005) have been identified. Although the functional circuits involving these neurons in the control of BAT thermogenesis remain to be delineated, the available data supports a role of the PVH, PAG, POA. Future studies are warranted to further understand the role of melanocortin system and other neuronal pathways contributing to the regulation of SNS-mediated BAT thermogenesis. 
The revitalized interest in understanding the role of BAT thermogenesis in obesity is largely due to the recent demonstration that BAT exists in substantial amount in adult humans (Nedergaard et al., 2007; Enerback, 2010b; Nedergaard and Cannon, 2010; Ouellet et al., 2011; Richard and Picard, 2011; Yoneshiro et al., 2011b). In addition, new sites (such as epicardial adipose tissue) exhibiting the presence of brown adipocytes are being recognized in humans. Our recent observations demonstrating

\section{REFERENCES}

Andrews, J. F., Richard, D., Jennings, G., and Trayhurn, P. (1986). Brown adipose tissue thermogenesis during pregnancy in mice. Ann. Nutr. Metab. 30, 87-93.

Au-Yong, I. T., Thorn, N., Ganatra, R., Perkins, A. C., and Symonds, M. E. (2009). Brown adipose tissue and seasonal variation in people. Diabetes 58, 2583-2587.

Bachman, E. S., Dhillon, H., Zhang, C. Y., Cinti, S., Bianco, A. C., Kobilka, B. K., and Lowell, B. B. (2002). Beta AR signaling required for dietinduced thermogenesis and obesity resistance. Science 297, 843-845.

Balthasar, N., Dalgaard, L. T., Lee, C. E., Yu, J., Funahashi, H., Williams, T., Ferreira, M., Tang, V., R. A. McGovern, Kenny, C. D., Christiansen, L. M., Edelstein, E., Choi, B., Boss, O., Aschkenasi, C., Zhang, C. Y., Mountjoy, K., Kishi, T., Elmquist, J. K., and Lowell, B. B. (2005). Divergence of melanocortin pathways in the control of food intake and energy expenditure. Cell 123, 493-505.

Bartness, T. J., and Song, C. K. (2007). Brain-adipose tissue neural crosstalk. Physiol. Behav. 91, 343-351.

Bartness, T. J., Vaughan, C. H., and Song, C. K. (2010). Sympathetic and sensory innervation of brown adipose tissue. Int. J. Obes. (Lond.) 34(Suppl. 1), S36-S42.

Berthoud, H. R., and Morrison, C. (2008). The brain, appetite, and obesity. Annu. Rev. Psychol. 59, 55-92.

Butler, A. A. (2006). The melanocortin system and energy balance. Peptides 27, 281-290.

Cannon, B., and Nedergaard, J. (2004). Brown adipose tissue: function and physiological significance. Physiol. Rev. 84, 277-359.

Cannon, B., and Nedergaard, J. (2008). Developmental biology: neither fat nor flesh. Nature 454, 947-948.

Cannon, B., and Nedergaard, J. (2010). Metabolic consequences of the presence or absence of the thermogenic capacity of brown adipose tissue in mice (and probably in humans). Int. J. Obes. (Lond.) 34(Suppl. 1), S7-S16.
Cohade, C., Mourtzikos, K. A., and Wahl, R. L. (2003a). "USA-fat": prevalence is related to ambient outdoor temperature-evaluation with 18F-FDG PET/CT. J. Nucl. Med. 44, 1267-1270.

Cohade, C., Osman, M., Pannu, H. K., and Wahl, R. L. (2003b). Uptake in supraclavicular area fat ("USA-fat"): description on 18F-FDG PET/CT. J. Nucl. Med. 44, 170-176.

Corander, M. P., and Coll, A. P. (2011). Melanocortins and body weight regulation: glucocorticoids, agoutirelated protein and beyond. Eur. J. Pharmacol. 660, 111-118.

Cypess, A. M., Lehman, S., Williams, G., Tal, I., Rodman, D., Goldfine, A. B., Kuo, F. C., Palmer, E. L., Tseng, Y. H., Doria, A., Kolodny, G. M., and Kahn, C. R. (2009). Identification and importance of brown adipose tissue in adult humans. N. Engl. J. Med. 360, 1509-1517.

De Jonghe, B. C., Hayes, M. R., and Bence, K. K. (2011). Melanocortin control of energy balance: evidence from rodent models. Cell. Mol. Life Sci. 68, 2569-2588.

de Menezes, R. C., Zaretsky, D. V., Fontes, M. A., and DiMicco, J. A. (2006). Microinjection of muscimol into caudal periaqueductal gray lowers body temperature and attenuates increases in temperature and activity evoked from the dorsomedial hypothalamus. Brain Res. 1092, 129-137.

Drubach, L. A., Palmer, E. L. III, Connolly, L. P., Baker, A., Zurakowski, D., and Cypess, A. M. (2011). Pediatric brown adipose tissue: detection, epidemiology, and differences from adults. J. Pediatr. 159, 939-944.

Enerback, S. (2010a). Human brown adipose tissue. Cell Metab. 11, 248-252.

Enerback, S. (2010b). Brown adipose tissue in humans. Int. J. Obes. 34, S43-S46.

Farooqi, S., and O'Rahilly, S. (2006). Genetics of obesity in humans.

Feldmann, H. M., Golozoubova, V., Cannon, B., and Nedergaard, J. (2009). UCP1 ablation induces obesity and abolishes diet-induced Endocr. Rev. 27, 710-718.

that BAT is involved in non-shivering thermogenesis in humans (Ouellet et al., 2012), coupled with the observations that ${ }^{18} \mathrm{FDG}$ uptake in BAT was blunted by aging and fatness tend to support the view that BAT-mediated thermogenesis is a critical player in human energy balance. Indeed, a better understanding of factors affecting the prevalence, distribution, and regulation of BAT thermogenesis would open up new avenues for intervening with human obesity.

thermogenesis in mice exempt from thermal stress by living at thermoneutrality. Cell Metab. 9, 203-209.

Festuccia, W. T., Oztezcan, S., Laplante, M., Berthiaume, M., Michel, C., Dohgu, S., Denis, R. G., Brito, M. N., Brito, N. A., Miller, D. S., Banks, W. A., Bartness, T. J., Richard, D., and Deshaies, Y. (2008). Peroxisome proliferator-activated receptor-gamma-mediated positive energy balance in the rat is associated with reduced sympathetic drive to adipose tissues and thyroid status. Endocrinology 149, 2121-2130.

Garcia, C. A., Van, D. Nostrand, Atkins, F., Acio, E., Butler, C., Esposito, G., Kulkarni, K., and Majd, M. (2006). Reduction of brown fat 2-deoxy2-[F-18]fluoro-D-glucose uptake by controlling environmental temperature prior to positron emission tomography scan. Mol. Imaging Biol. $8,24-29$.

Garfield, A. S., Lam, D. D., Marston, O. J., Przydzial, M. J., and Heisler, L. K. (2009). Role of central melanocortin pathways in energy homeostasis. Trends Endocrinol. Metab. 20, 203-215.

Gelez, H., Poirier, S., Facchinetti, P., Allers, K. A., Wayman, C., Alexandre, L., and Giuliano, F. (2010). Neuroanatomical evidence for a role of central melanocortin-4 receptors and oxytocin in the efferent control of the rodent clitoris and vagina. $J$. Sex. Med. 7, 2056-2067.

Gelfand, M. J., O'Hara M. S, Curtwright, L. A., and Maclean, J. R. (2005). Premedication to block [(18)F]FDG uptake in the brown adipose tissue of pediatric and adolescent patients. Pediatr. Radiol. 35, 984-990.

Gessner, K. (1551). Conradi Gesneri medici Tigurine Historiae Animalium Lib. I de Quadripedibus uiuiparis, 842 .

Ghamari-Langroudi, M., Srisai, D., and Cone, R. D. (2011). Multinodal regulation of the arcuate/paraventricular nucleus circuit by leptin. Proc. Natl. Acad. Sci. U.S.A. 108, 355-360.

Goodbody, A. E., and Trayhurn, P. (1981). GDP binding to brown- adipose-tissue mitochondria of diabetic - obese $(\mathrm{db} / \mathrm{db})$ mice. Decreased binding in both the obese and pre-obese states. Biochem. J. 194, 1019-1022.

Grill, H. J. (2006). Distributed neural control of energy balance: contributions from hindbrain and hypothalamus. Obesity (Silver Spring) 14(Suppl. 5), 216S-221S.

Guo, Z. L., and Longhurst, J. C. (2010). Activation of reciprocal pathways between arcuate nucleus and ventrolateral periaqueductal gray during electroacupuncture: involvement of VGLUT3. Brain Res. 1360, 77-88.

Hadi, M., Chen, C. C., Whatley, M., Pacak, K., and Carrasquillo, J. A. (2007). Brown fat imaging with (18)F-6-fluorodopamine PET/CT, (18)F-FDG PET/CT, and (123)I-MIBG SPECT: a study of patients being evaluated for pheochromocytoma. J. Nucl. Med. 48, 1077-1083.

Hany, T. F., Gharehpapagh, E., Kamel, E. M., Buck, A., Himms-Hagen, J., and von Schulthess, G. K. (2002). Brown adipose tissue: a factor to consider in symmetrical tracer uptake in the neck and upper chest region. Eur. J. Nucl. Med. Mol. Imaging 29, 1393-1398.

Herzog, H. (2003). Neuropeptide Y and energy homeostasis: insights from $\mathrm{Y}$ receptor knockout models. Eur. J. Pharmacol. 480, 21-29.

Huttunen, P., Hirvonen, J., and Kinnula, V. (1981). The occurrence of brown adipose tissue in outdoor workers. Eur. J. Appl. Physiol. Occup. Physiol. 46, 339-345.

Jacobsson, H., Bruzelius, M., and Larsson, S. A. (2005). Reduction of FDG uptake in brown adipose tissue by propranolol. Eur. J. Nucl. Med. Mol. Imaging 32, 1130.

Jimenez, M., Leger, B., Canola, K., Lehr, L., Arboit, P., Seydoux, J., Russell, A. P., Giacobino, J. P., Muzzin, P., and Preitner, F. (2002). Beta(1)/beta(2)/beta(3)adrenoceptor knockout mice are obese and cold-sensitive but have normal lipolytic responses to fasting. FEBS Lett. 530, 37-40. 
Kajimura, S., Seale, P., and Spiegelman, B. M. (2010). Transcriptional control of brown fat development. Cell Metab. 11, 257-262.

Kim, S., Krynyckyi, B. R., Machac, J., and Kim, C. K. (2008). Temporal relation between temperature change and FDG uptake in brown adipose tissue. Eur. J. Nucl. Med. Mol. Imaging 35, 984-989.

Kontani, Y., Wang, Y., Kimura, K., Inokuma, K. I., Saito, M., SuzukiMiura, T., Wang, Z., Sato, Y., Mori, N., and Yamashita, H. (2005). UCP1 deficiency increases susceptibility to diet-induced obesity with age. Aging Cell 4, 147-155.

Kozak, L. P., and Anunciado-Koza, R. (2008). UCP1: its involvement and utility in obesity. Int. J. Obes. (Lond.) 32(Suppl. 7), S32-S38.

Kuji, I., Imabayashi, E., Minagawa, A., Matsuda, H., and Miyauchi, T. (2008). Brown adipose tissue demonstrating intense FDG uptake in a patient with mediastinal pheochromocytoma. Ann. Nucl. Med. 22, 231-235.

Labbe, S. M., Croteau, E., GrenierLarouche, T., Frisch, F., Ouellet, R., Langlois, R., Guerin, B., Turcotte, E. E., and Carpentier, A. C. (2011). Normal postprandial nonesterified fatty acid uptake in muscles despite increased circulating Fatty acids in type 2 diabetes. Diabetes 60 , 408-415.

Landsberg, L., Saville, M. E., and Young, J. B. (1984). Sympathoadrenal system and regulation of thermogenesis. Am. J. Physiol. 247(Pt 1), E181E189.

Li, P., Tjen-A-Looi, S. C., Guo, Z. L., and Longhurst, J. C. (2010a). An arcuate-ventrolateral periaqueductal gray reciprocal circuit participates in electroacupuncture cardiovascular inhibition. Auton. Neurosci. 158, 13-23.

Li, P., Tjen-A-Looi, S. C., and Longhurst, J. C. (2010b). Nucleus raphe pallidus participates in midbrain-medullary cardiovascular sympathoinhibition during electroacupuncture. Am. J. Physiol. Regul. Integr. Comp. Physiol. 299, R1369-R1376.

Lowell, B. B., and Bachman, E. S. (2003). Beta-Adrenergic receptors, diet-induced thermogenesis, and obesity. $J$. Biol. Chem. 278, 29385-29388.

Marchington, D., Rothwell, N. J., Stock, M. J., and York, D. A. (1983). Energy balance, diet-induced thermogenesis and brown adipose tissue in lean and obese (fa/fa) Zucker rats after adrenalectomy. J. Nutr. 113, 1395-1402.
Morrison, S. F. (1999). RVLM and raphe differentially regulate sympathetic outflows to splanchnic and brown adipose tissue. Am. J. Physiol. 276( $\mathrm{Pt}$ 2), R962-R973.

Morrison, S. F. (2011). Carl Ludwig distinguished lectureship of the APS neural control and autonomic regulation section: central neural pathways for thermoregulatory cold defense. J. Appl. Physiol. 110, 1137-1149.

Mountjoy, K. G. (2010). Functions for pro-opiomelanocortin-derived peptides in obesity and diabetes. Biochem. J. 428, 305-324.

Nakamura, K. (2011). Invited review: central circuitries for body temperature regulation and fever. Am. J. Physiol. Regul. Integr. Comp. Physiol. 301, R1207-R1208.

Nakamura, Y., Nakamura, K., Matsumura, K., Kobayashi, S., Kaneko, T., and Morrison, S. F. (2005). Direct pyrogenic input from prostaglandin EP3 receptor-expressing preoptic neurons to the dorsomedial hypothalamus. Eur. J. Neurosci. 22, 3137-3146.

Nedergaard, J., Bengtsson, T., and Cannon, B. (2007). Unexpected evidence for active brown adipose tissue in adult humans. Am. J. Physiol. Endocrinol. Metab. 293, E444-E452.

Nedergaard, J., and Cannon, B. (2010). The changed metabolic world with human brown adipose tissue: therapeutic visions. Cell Metab. 11, 268-272.

Nedergaard, J., Golozoubova, V., Matthias, A., Shabalina, I., Ohba, K., Ohlson, K., Jacobsson, A., and Cannon, B. (2001). Life without UCP1: mitochondrial, cellular and organismal characteristics of the UCP1-ablated mice. Biochem. Soc. Trans. 29(Pt 6), 756-763.

Nguyen, A. D., Herzog, H., and Sainsbury, A. (2011). Neuropeptide Y and peptide YY: important regulators of energy metabolism. Curr. Opin. Endocrinol. Diabetes Obes. 18, 56-60.

Nicholls, D. G., and Locke, R. M. (1984). Thermogenic mechanisms in brown fat. Physiol. Rev. 64, 1-64.

Ouellet, V., Labbe, S. M., Blondin, D. P., Phoenix, S., Guerin, B., Haman, F., Turcotte, E. E., Richard, D., and Carpentier, A. C. (2012). Brown adipose tissue oxidative metabolism contributes to energy expenditure during acute cold exposure in humans. J. Clin. Invest. 122, 545-552.

Ouellet, V., Routhier-Labadie, A., Bellemare, W., Lakhal-Chaieb, L., Turcotte, E., Carpentier, A.
C., and Richard, D. (2011). Outdoor temperature, age, sex, body mass index, and diabetic status determine the prevalence, mass, and glucose-uptake activity of 18F-FDG-detected BAT in humans. J. Clin. Endocrinol. Metab. 96, 192-199.

Pandit, R., de Jong, J. W., Vanderschuren, L. J., and Adan, R. A. (2011). Neurobiology of overeating and obesity: the role of melanocortins and beyond. Eur. J. Pharmacol. 660 28-42.

Parysow, O., Mollerach, A. M., Jager, V., Racioppi, S., San, J. Roman, and Gerbaudo, V. H. (2007). Low-dose oral propranolol could reduce brown adipose tissue F-18 FDG uptake in patients undergoing PET scans. Clin. Nucl. Med. 32, 351-357.

Quevedo, S., Roca, P., Pico, C., and Palou, A. (1998). Sex-associated differences in cold-induced UCP1 synthesis in rodent brown adipose tissue. Pflugers Arch. 436, 689-695.

Rathner, J. A., and Morrison, S. F. (2006). Rostral ventromedial periaqueductal gray: a source of inhibition of the sympathetic outflow to brown adipose tissue. Brain Res. 1077, 99-107.

Richard, D. (2007). Energy expenditure: a critical determinant of energy balance with key hypothalamic controls. Minerva Endocrinol. 32, 173-183.

Richard, D., Carpentier, A. C., Dore, G., Ouellet, V., and Picard, F. (2010). Determinants of brown adipocyte development and thermogenesis. Int. J. Obes. (Lond.) 34(Suppl. 2), S59-S66.

Richard, D., Guesdon, B., and Timofeeva, E. (2009). The brain endocannabinoid system in the regulation of energy balance. Best Pract. Res. Clin. Endocrinol. Metab. 23 17-32.

Richard, D., and Picard, F. (2011). Brown fat biology and thermogenesis. Front. Biosci. 16, 1233-1260.

Rodriguez, E., Monjo, M., RodriguezCuenca, S., Pujol, E., Amengual, B. Roca, P., and Palou, A. (2001). Sexual dimorphism in the adrenergic control of rat brown adipose tissue response to overfeeding. Pflugers Arch. 442, 396-403.

Rodriguez-Cuenca, S., Pujol, E., Justo, R., Frontera, M., Oliver, J., Gianotti, M., and Roca, P. (2002). Sexdependent thermogenesis, differences in mitochondrial morphology and function, and adrenergic response in brown adipose tissue. $J$. Biol. Chem. 277, 42958-42963.
Rothwell, N. J., and Stock, M. J. (1982). Effect of chronic food restriction on energy balance, thermogenic capacity, and brown-adipose-tissue activity in the rat. Biosci. Rep. 2, 543-549.

Rothwell, N. J., and Stock, M. J. (1983). Luxuskonsumption, dietinduced thermogenesis and brown fat: the case in favour. Clin. Sci. 64, 19-23.

Rousseau, C., Bourbouloux, E., Campion, L., Fleury, N., Bridji, B., Chatal, J. F., Resche, I., and Campone, M. (2006). Brown fat in breast cancer patients: analysis of serial (18)FFDG PET/CT scans. Eur. J. Nucl. Med. Mol. Imaging 33, 785-791.

Sacks, H. S., and Fain, J. N. (2011). Human epicardial fat: what is new and what is missing? Clin. Exp. Pharmacol. Physiol. 38, 879-887.

Sacks, H. S., Fain, J. N., Holman, B., Cheema, P., Chary, A., Parks, F., Karas, J., Optican, R., Bahouth, S. W., Garrett, E., Wolf, R. Y., Carter, R. A., Robbins, T., Wolford, D., and Samaha, J. (2009). Uncoupling protein-1 and related messenger ribonucleic acids in human epicardial and other adipose tissues: epicardial fat functioning as brown fat. J. Clin. Endocrinol. Metab. 94, 3611-3615.

Saito, M., Okamatsu-Ogura, Y., Matsushita, M., Watanabe, K., Yoneshiro, T., Nio-Kobayashi, J., Iwanaga, T., Miyagawa, M., Kameya, T., Nakada, K., Kawai, Y., and Tsujisaki, M. (2009). High incidence of metabolically active brown adipose tissue in healthy adult humans: effects of cold exposure and adiposity. Diabetes 58 , 1526-1531.

Schoeller, D. A. (2001). The importance of clinical research: the role of thermogenesis in human obesity. Am. J. Clin. Nutr. 73, 511-516.

Seale, P. (2010). Transcriptional control of brown adipocyte development and thermogenesis. Int. J. Obes. (Lond.) 34(Suppl. 1), S17-S22.

Seale, P., Bjork, B., Yang, W., Kajimura, S., Chin, S., Kuang, S., Scime, A., Devarakonda, S., Conroe, H. M. Erdjument-Bromage, H., Tempst, P., Rudnicki, M. A., Beier, D. R., and Spiegelman, B. M. (2008). PRDM16 controls a brown fat/skeletal muscle switch. Nature 454, 961-967.

Sell, H., Deshaies, Y., and Richard, D. (2004a). The brown adipocyte: update on its metabolic role. Int. J. Biochem. Cell Biol. 36, 2098-2104.

Sell, H., Berger, J. P., Samson, P., Castriota, G., Lalonde, J., Deshaies, Y., 
and Richard, D. (2004b). Peroxisome proliferator-activated receptor gamma agonism increases the capacity for sympathetically mediated thermogenesis in lean and ob/ob mice. Endocrinology 145, 3925-3934.

Soderlund, V., Larsson, S. A., and Jacobsson, H. (2007). Reduction of FDG uptake in brown adipose tissue in clinical patients by a single dose of propranolol. Eur. J. Nucl. Med. Mol. Imaging 34, 1018-1022.

Song, C. K., Jackson, R. M., Harris, R. B., Richard, D., and Bartness, T. J. (2005). Melanocortin-4 receptor mRNA is expressed in sympathetic nervous system outflow neurons to white adipose tissue. Am. J. Physiol. Regul. Integr. Comp. Physiol. 289, R1467-R1476.

Song, C. K., Vaughan, C. H., KeenRhinehart, E., Harris, R. B., Richard, D., and Bartness, T. J. (2008). Melanocortin-4 receptor mRNA expressed in sympathetic outflow neurons to brown adipose tissue: neuroanatomical and functional evidence. Am. J. Physiol. Regul. Integr. Comp. Physiol. 295, R417-R428.

Ste, L. Marie, Miura, G. I., Marsh, D. J., Yagaloff, K., and Palmiter, R. D. (2000). A metabolic defect promotes obesity in mice lacking melanocortin-4 receptors. Proc. Natl. Acad. Sci. U.S.A. 97, 12339-12344.

Tao, Y. X. (2010). The melanocortin-4 receptor: physiology, pharmacology, and pathophysiology. Endocr. Rev. 31, 506-543.

Tatsumi, M., Engles, J. M., Ishimori, T., Nicely, O., Cohade, C., and Wahl, R. L. (2004). Intense (18)F-FDG uptake in brown fat can be reduced pharmacologically. J. Nucl. Med. 45, 1189-1193.

Trayhurn, P., Jones, P. M., M. M. McGuckin, and Goodbody, A. E. (1982). Effects of overfeeding on energy balance and brown fat thermogenesis in obese (ob/ob) mice. Nature 295, 323-325.

Trayhurn, P., and Richard, D. (1985). Brown adipose tissue thermogenesis and the energetics of pregnancy and lactation in rodents. Biochem. Soc. Trans. 13, 826-828.

Truong, M. T., Erasmus, J. J., Munden, R. F., Marom, E. M., Sabloff, B. S., Gladish, G. W., Podoloff, D. A., and Macapinlac, H. A. (2004). Focal FDG uptake in mediastinal brown fat mimicking malignancy: a potential pitfall resolved on PET/CT. AJR Am. J. Roentgenol. 183, 1127-1132.

Tseng, Y. H., Kokkotou, E., Schulz, T. J., Huang, T. L., Winnay, J. N., Taniguchi, C. M., Tran, T. T., Suzuki, R., Espinoza, D. O., Yamamoto, Y., Ahrens, M. J., Dudley, A. T., Norris, A. W., Kulkarni, R. N., and Kahn, C. R. (2008). New role of bone morphogenetic protein 7 in brown adipogenesis and energy expenditure. Nature 454, 1000-1004.

Valle, A., Garcia-Palmer, F. J., Oliver, J., and Roca, P. (2007). Sex differences in brown adipose tissue thermogenic features during caloric restriction. Cell. Physiol. Biochem. 19, 195-204.

van Marken Lichtenbelt, W. D., Vanhommerig, J. W., Smulders, N. M., Drossaerts, J. M., Kemerink, G. J., Bouvy, N. D., Schrauwen, P., and Teule, G. J. (2009). Cold-activated brown adipose tissue in healthy men. N. Engl. J. Med. 360, 1500-1508.
Virtanen, K. A., Lidell, M. E., Orava, J. Heglind, M., Westergren, R., Niemi, T., Taittonen, M., Laine, J., Savisto, N. J., Enerback, S., and Nuutila, P. (2009). Functional brown adipose tissue in healthy adults. N. Engl. J. Med. 360, 1518-1525.

Wang, Q., Zhang, M., Ning, G., Gu, W., Su, T., Xu, M., Li, B., and Wang, W. (2011). Brown adipose tissue in humans is activated by elevated plasma catecholamines levels and is inversely related to central obesity. PLOS ONE 6, e21006. doi:10.1371/journal.pone.0021006

Yamaga, L. Y., Thom, A. F., Wagner, J., Baroni, R. H., Hidal, J. T., and Funari, M. G. (2008). The effect of catecholamines on the glucose uptake in brown adipose tissue demonstrated by (18)F-FDG PET/CT in a patient with adrenal pheochromocytoma. Eur. J. Nucl. Med. Mol. Imaging 35, 446-447.

Yoneshiro, T., Aita, S., Matsushita, M. Okamatsu-Ogura, Y., Kameya, T., Kawai, Y., Miyagawa, M., Tsujisaki, M., and Saito, M. (2011a). Agerelated decrease in cold-activated brown adipose tissue and accumulation of body fat in healthy humans. Obesity (Silver Spring) 19 1755-1760.

Yoneshiro, T., Aita, S., Matsushita, M. Kameya, T., Nakada, K., Kawai, Y., and Saito, M. (2011b). Brown adipose tissue, whole-body energy expenditure, and thermogenesis in healthy adult men. Obesity (Silver Spring) 19, 13-16.

Zhang, Y., Kilroy, G. E., Henagan, T. M., Prpic-Uhing, V., Richards, W. G., Bannon, A. W., Mynatt, R. L., and Gettys, T. W. (2005). Targeted deletion of melanocortin receptor subtypes 3 and 4, but not CART, alters nutrient partitioning and compromises behavioral and metabolic responses to leptin. FASEB J. 19, 1482-1491.

Zingaretti, M. C., Crosta, F., Vitali, A., Guerrieri, M., Frontini, A. Cannon, B., Nedergaard, J., and Cinti, S. (2009). The presence of UCP1 demonstrates that metabolically active adipose tissue in the neck of adult humans truly represents brown adipose tissue. FASEB J. 23, 3113-3120.

Conflict of Interest Statement: The authors declare that the research was conducted in the absence of any commercial or financial relationships that could be construed as a potential conflict of interest.

Received: 25 October 2011; paper pending published: 20 November 2011; accepted: 13 February 2012; published online: 27 February 2012.

Citation: Richard D, Monge-Roffarello B, Chechi K, Labbé SM and Turcotte EE (2012) Control and physiological determinants of sympathetically mediated brown adipose tissue thermogenesis. Front. Endocrin. 3:36. doi: 10.3389/fendo.2012.00036

This article was submitted to Frontiers in Cellular Endocrinology, a specialty of Frontiers in Endocrinology.

Copyright (c) 2012 Richard, MongeRoffarello, Chechi, Labbé and Turcotte. This is an open-access article distributed under the terms of the Creative Commons Attribution Non Commercial License, which permits non-commercial use, distribution, and reproduction in other forums, provided the original authors and source are credited. 